\author{
Л. Грубчин ${ }^{1,2}$, Ю. Б. Гуров ${ }^{1,3}$, Б. Затько ${ }^{2}$, О. М. Иванов ${ }^{1}$, \\ С. В. Митрофанов ${ }^{1}$, С. В. Розов ${ }^{1}$, В. Г. Сандуковский ${ }^{1}$, \\ В. А. Семин ${ }^{1}$, В. А. Скуратов ${ }^{1}$
}

\title{
ИССЛЕДОВАНИЕ РАДИАЦИОННОЙ СТОЙКОСТИ Si- И SiC-ДЕТЕКТОРОВ НА ПУЧКЕ ИОНОВ Хе
}

Направлено в журнал «Приборы и техника эксперимента»

${ }^{1}$ Объединенный институт ядерных исследований, Дубна

2 Электротехнический институт, Словацкая академия наук, Братислава

${ }^{3}$ Национальный исследовательский ядерный университет «МИФИ», Москва 
Грубчин Л. и др.

P13-2017-81

Исследование радиационной стойкости $\mathrm{Si}$ - и $\mathrm{SiC}$-детекторов на пучке ионов Хе

Представлены результаты исследования характеристик детекторов на основе кремния $(\mathrm{Si})$ и карбида кремния $4 \mathrm{H}-\mathrm{SiC}$ при облучении различными интегральными потоками ионов ксенона (Хе). Облучения проводились на циклотроне IC-100 в Лаборатории ядерных реакций им. Г.Н. Флерова ОИЯИ. Показано, что ухудшение работоспособности $\mathrm{SiC}$-п. п. д. наступает при более высоких дозовых нагрузках, чем при использовании $\mathrm{Si}$-детекторов.

Работа выполнена в Лаборатории ядерных проблем им. В.П.Джелепова ОИЯИ.

Hrubčín L. et al. P13-2017-81

Investigation of Radiation Hardness of $\mathrm{Si}$ and $\mathrm{SiC}$ Detectors by Xe Ion Beam

The properties of silicon and silicon carbide $(\mathrm{SiC})$ detectors after their irradiation by different doses of xenon ions are presented. The irradiation of detectors was carried out at the IC-100 cyclotron at the Flerov Laboratory of Nuclear Reactions of JINR. It is shown that the degradation of spectroscopy characteristics of $\mathrm{SiC}$ detectors takes place at higher dose than the similar Si detectors used at experiments.

The investigation has been performed at the Dzhelepov Laboratory of Nuclear Problems, JINR. 


\section{ВВЕДЕНИЕ}

Кремниевые полупроводниковые детекторы (Si-п. п. д.), которые широко используются в физике низких и высоких энергий, достаточно чувствительны к радиационным повреждениям. При прохождении ионизирующей частицы в базовом материале могут возникать нарушения кристаллической решетки: смещения и выбивания атомов из узлов решетки, изменение изотопного состава в результате ядерных реакций. Данные процессы приводят к образованию центров захвата и рекомбинации носителей заряда, а также к изменению их эффективной (донорной, акцепторной) концентрации. Большие дозы облучения п. п. д. приводят к заметному ухудшению энергетического разрешения и уменьшению амплитуды сигнала, что, соответственно, обусловлено уменьшением времени жизни носителей и неполным собиранием заряда.

В последние годы для создания радиационно стойких приборов активно применяется карбид кремния (политип 4H-SiC) $[1,2]$. Это обусловлено тем, что данный материал по сравнению с кремнием имеет бо́льшие значения ширины запрещенной зоны (в 3 раза) и пороговой энергии дефектообразования (в 2 раза).

В работе исследовались характеристики детекторов на основе кремния (Si) и карбида кремния 4H-SiC при облучении различными интегральными потоками ионов ксенона $(\mathrm{Xe)}$. Облучения проводились на циклотроне IC-100 в Лаборатории ядерных реакций им. Г. Н. Флерова ОИЯИ [3].

\section{ХАРАКТЕРИСТИКИ ДЕТЕКТОРОВ}

Для измерений использовались по два детектора: на основе $\mathrm{Si}$ и $\mathrm{SiC}$.

$\mathrm{Si}$-детекторы изготовлены по планарной технологии [4] из кремния $n$-типа (с удельным сопротивлением $\rho \approx 6$ кОм·см). Выпрямляющие и омические контакты формировались имплантацией бора и фосфора (толщиной «мертвого» слоя со стороны $p-n$-перехода 60 нм). Детекторы имели активную площадь $8 \times 8$ мм и толщину 300 мкм.

$\mathrm{SiC}$-детекторы $[5,6]$ были изготовлены в Электротехническом институте (Словацкая академия наук, Братислава) на основе эпитаксиального слоя $4 \mathrm{H}-\mathrm{SiC} n$-типа проводимости, который был получен методом эпитаксиального выращивания из жидкой фазы на проводящих $n^{+}$-подложках $4 \mathrm{H}-\mathrm{SiC}$ фирмы «L.P.Е.» (Италия). Диаметр исходной подложки 3", толщина 350 мкм, концентрация примеси $\sim 2 \cdot 10^{18} \mathrm{~cm}^{-3}$. Созданные эпитаксиальные слои имели толщину 102 мкм и концентрацию донорной (азотной) примеси $2 \cdot 10^{14} \mathrm{~cm}^{-3}$. Детекторы изготавливались на образцах размером $6 \times 6$ мм. Выпрямляющие контакты $\varnothing 1,4$ мм создавались вакуумным напылением двойного слоя из $\mathrm{Ni}$ и $\mathrm{Au}$ соответственно толщиной 40 и 80 нм. Омический контакт изготавливался аналогичным образом, при этом напыление проводилось на всю заднюю поверхность образца. 
На основе измеренных вольт-амперных и вольт-фарадных характеристик было установлено, что рабочее напряжение на $\mathrm{Si}$ - и $\mathrm{SiC}$-детекторах составляет соответственно 40 и 120 В. Для всех детекторов исходное энергетическое разрешение, измеренное для $\alpha$-частиц с энергией $E \approx 5,5 \mathrm{MэB}$, не превышало 25 кэВ.

\section{МЕТОДИКА И РЕЗУЛЬТАТЫ ИЗМЕРЕНИЙ}

Облучение образцов проводилось пучком ионов ${ }^{132} \mathrm{Xe}^{26+}$ с энергией 165 МэВ. Схема измерений для определения радиационной стойкости детекторов представлена на рис. 1. Детекторы размещались в вакуумной камере.

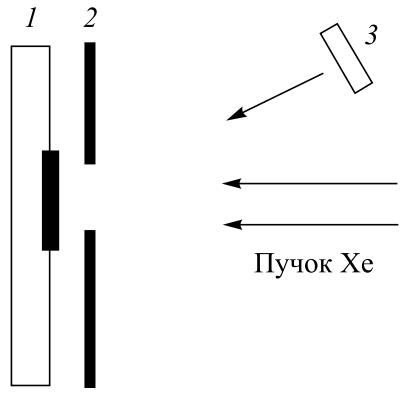

Рис. 1. Схема измерений: 1 - детектор; 2 - коллиматор; $3-\alpha$-источник ${ }^{226} \mathrm{Ra}$

Пучок ионов попадал на них через коллиматор $\varnothing 6$ мм. В камере на достаточно удаленном расстоянии от траектории пучка также размещался $\alpha$-источник ${ }^{226} \mathrm{Ra}\left(E_{\alpha} \approx 4,8,5,5,6,0,7,7 \mathrm{MэB}\right)$, который использовался для постоянного тестирования стабильности характеристик исследуемых детекторов.

$\mathrm{Si}$-детекторы облучались ионами Хе с интегральными дозами от $1,2 \cdot 10^{6}$ до $2,6 \cdot 10^{7} \mathrm{~cm}^{-2}$. На рис. 2 показаны спектры ионов Хе, измеренные одним из $\mathrm{Si}$-п. п. д. при внедренных дозах $3,5 \cdot 10^{6}$ и $2,6 \cdot 10^{7} \mathrm{~cm}^{-2}$. В первых каналах спектров наблюдаются $\alpha$-пики от тестового источника ${ }^{226} \mathrm{Ra}$. Видно, что с увеличением дозы облучения происходит ухудшение энергетического разрешения $(\Delta E / E$, где $\Delta E-$ ПШПВ, $E-$ энергия) и уменьшение амплитуды сигнала на $\mathrm{Si}$-детекторах. В табл. 1 показаны усредненные характеристики этих детекторов, определенные с помощью ионов Хе и $\alpha$-частиц $\left(E_{\alpha} \approx 7,7 \mathrm{MэB}\right)$ при разных дозах облучения.

$\mathrm{SiC}$-детекторы облучались ионами Хе с интегральными дозами от $1,9 \cdot 10^{7}$ до $2,3 \cdot 10^{9} \mathrm{~cm}^{-2}$. Следует отметить, что максимальное значение дозы на

Таблица 1. Характеристики $\mathrm{Si}$-детекторов, полученные при облучении ионами Хе с разными дозами

\begin{tabular}{|l|c|c|c|c|}
\hline \multirow{2}{*}{ Доза, см } & \multicolumn{2}{|c|}{$\begin{array}{c}\text { Энергетическое } \\
\text { разрешение } \Delta E / E, \%\end{array}$} & \multicolumn{2}{c|}{$\begin{array}{c}\text { Уменьшение } \\
\text { амплитуды сигнала, \% }\end{array}$} \\
\cline { 2 - 5 } & ионы Хе & $\alpha$-частицы & ионы Хе & $\alpha$-частицы \\
\hline $1,2 \cdot 10^{6}$ & 6 & 0,9 & 5 & 2 \\
$3,5 \cdot 10^{6}$ & 7 & 1,1 & 18 & 8 \\
$2,6 \cdot 10^{7}$ & 9 & 1,4 & 50 & 30 \\
\hline
\end{tabular}




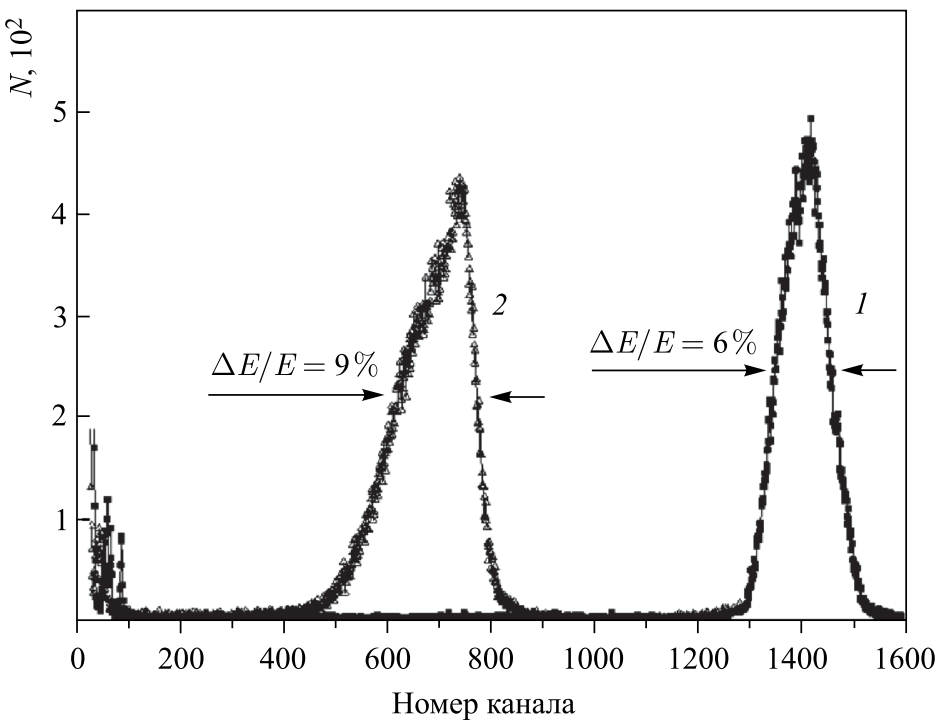

Рис. 2. Спектры ионов Хе, измеренные $\mathrm{Si}$-п.п.д. при дозах $3,5 \cdot 10^{6}$ (1) и $2,6 \cdot 10^{7} \mathrm{~cm}^{-2}(2)$

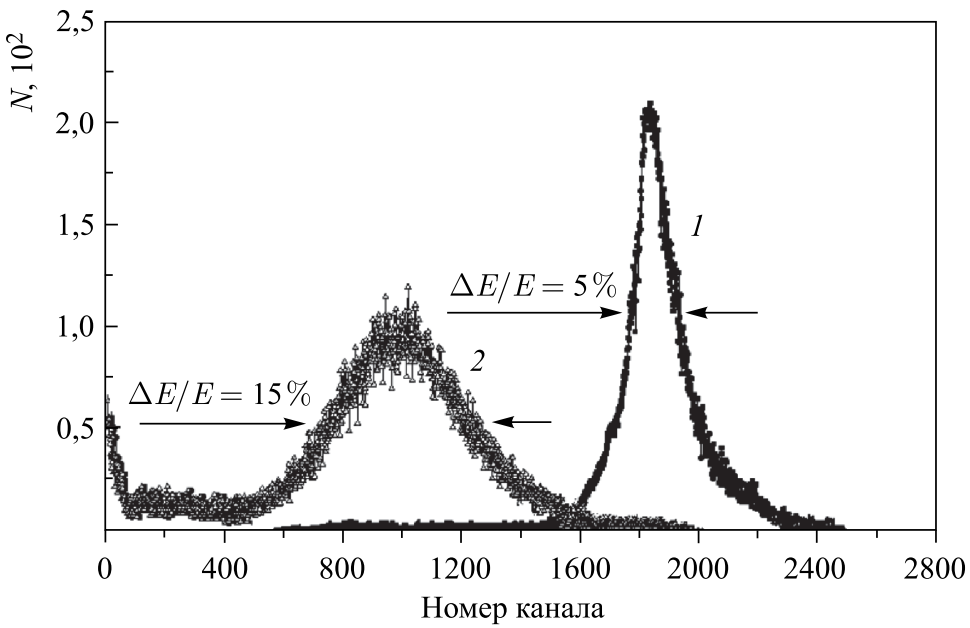

Рис. 3. Спектры ионов Хе, измеренные $\mathrm{SiC}$-п. п.д. при дозах $1,9 \cdot 10^{7} \mathrm{~cm}^{-2}$ (1) и $2,3 \cdot 10^{9} \mathrm{~cm}^{-2}(2)$

два порядка больше, чем при облучении кремниевых детекторов. Это было обусловлено повышенной радиационной стойкостью этих приборов. На рис. 3 показаны спектры ионов Хе, измеренные одним из $\mathrm{SiC}$-п. п. д. при внедренных дозах $1,9 \cdot 10^{7}$ и $2,3 \cdot 10^{9} \mathrm{~cm}^{-2}$. Как и для кремниевых счетчиков, наблюдается 
Таблица 2. Характеристики $\mathrm{SiC}$-детекторов, полученные при облучении ионами Хе

\begin{tabular}{|l|c|c|c|c|}
\hline \multirow{2}{*}{ Доза, см } & \multicolumn{2}{|c|}{ Энергетическое } & \multicolumn{2}{c|}{ Уменьшение } \\
& разрешение $\Delta E / E, \%$ & амплитуды сигнала, \% \\
\cline { 2 - 5 } & ионы Хе & $\alpha$-частицы & ионы Хе & $\alpha$-частицы \\
\hline $1,9 \cdot 10^{7}$ & 5 & 1,1 & 6 & 3 \\
$2,3 \cdot 10^{9}$ & 15 & 2,9 & 37 & 32 \\
\hline
\end{tabular}

деградация характеристик $\mathrm{SiC}$-детекторов, но при более высоких дозовых нагрузках. В табл. 2 показаны усредненные характеристики $\mathrm{SiC}$-детекторов, определенные с помощью ионов Хе и $\alpha$-частиц $\left(E_{\alpha} \approx 7,7\right.$ МэВ) при разных дозах облучения.

\section{ЗАКЛЮЧЕНИЕ}

Представленные характеристики детекторов на основе кремния и карбида кремния, которые облучались различными интегральными потоками ионов Xе ( $E=165$ МэB), показывают, что радиационная стойкость SiC-П. П.д. значительно выше, чем Si-детекторов. Следовательно, $\mathrm{SiC}$-детекторы могут быть использованы для длительного мониторирования пучков тяжелых ионов в прикладных задачах [3].

\section{ЛИТЕРАТУРА}

1. Bruzzia M., Sadrozinskib H.F.-W., Seiden A. // Nucl. Instr. Meth. A. 2007. V. 579. P. 754; doi:10.1016/j.nima.2007.05.326.

2. Kalinina E. V. // Semiconductors. 2007. V.41. P.745; doi:10.1134/S1063782607070019.

3. Gikal B.N., Gulbekyan G.G., Dmitriev S.N., Bogomolov S.L., Borisov O.N., Ivanenko I. A., Kazarinov N. Y., Kazacha V.I., Kalagin I. V., Kolesov I. V., Sazonov M. N., Tikhomirov A.V., Franko J. // Phys. Part. Nucl. Lett. 2010. V.7. P.557; doi:10.1134/S1547477110070289.

4. Bloch P., Cheremukhin A., Golubkov S., Golutvin I., Egorov N., Konjkov K., Kozlov Y., Peisert A., Sidorov A., Zamiatin N. // IEEE Trans. 2002. V. NS-49. P.321; doi:10.1109/TNS.2002.998662.

5. Dubecký F., Gombia E., Ferrari C., Zat'ko B., Vanko G., Baldini M., Kovac J., Bacek D., Kovac P., Hrkut P., Necas V. // JINST. 2012. V.7. P.P09005; doi:10.1088/17480221/7/09/P09005.

6. Гуров Ю.Б., Розов С.В., Сандуковский В. Г., Якушев Е. А., Hrubčín L., Zat’ko B. // ПТЭ. 2015. № 1. С. 29-31; doi:10.7868/S003281621501005X.

Получено 23 ноября 2017 г. 
Редактор Е. В. Григорьева

Подписано в печать 16.01.2018.

Формат $60 \times 90 / 16$. Бумага офсетная. Печать офсетная.

Усл. печ. л. 0,44. Уч.-изд. л. 0,51. Тираж 215 экз. Заказ № 59319.

Издательский отдел Объединенного института ядерных исследований 141980, г. Дубна, Московская обл., ул. Жолио-Кюри, 6.

E-mail: publish@jinr.ru

www.jinr.ru/publish/ 